\title{
Benefits of ISO 20000 IT service management certification
}

\author{
Santi Cots \\ santi.cots@udg.edu \\ Universitat de Girona \\ Servei Informàtic \\ Martí Casadesús \\ Professor \\ Universitat de Girona \\ Departament d'Organització, Gestió Empresarial i Desenvolupament de Producte
}

\author{
Frederic Marimon \\ Professor \\ Universitat International de Catalunya \\ Faculty of Economics and Social Sciences
}

\begin{abstract}
This paper explores the benefits organizations perceive that they have attained by their ISO 20000 service management system standard certification. The paper proposes a classification of benefits and tests the relationship between that classification and general satisfaction with the standard. The study is based on 105 responses to ISO20000-certified organisations survey in Spain. After a descriptive analysis of the sample, a structural equation model is designed to test the hypotheses presented. According to the model, ISO 20000 benefits can be divided into those which are internal and those which are external. The variables that best define each type are identified. Moreover, those benefits are shown to be related to general satisfaction with ISO 20000 certification. The findings can be extended to other IT service management (ITSM) standards such as ITIL.
\end{abstract}

Keywords: ISO 20000; ITIL; IT Service Management, Management Standards; SEM; Service Quality.

Article Classification: Research paper

\section{1- Introduction}

Most of the value obtained from information technology (IT) results, not from the technology itself, but from the services that can be built using it (Sandström et al., 
2008). This has led many IT providers to change their focus from technology to become more conscious of being service-oriented providers (Bitner, 2001; Cherbakov et al., 2005; Demirkan et al., 2008; Maglio et al., 2009). Such a move should be compatible with the need to industrialise and standardise those services (Brocke et al., 2010) and, therefore, make it appropriate to introduce formal service management techniques (Gupta et al., 2005) as a means to guarantee the quality of the services provided (Edvardsson, 1998).

To meet these needs, the Information Technology Service Management (ITSM) field has been developed to define, manage and deliver IT services (Keel et al., 2007; Winniford et al., 2009; Iden and Eikebrokk, 2013). ITSM can be considered a subtopic of the more general Service Science (Galup et al., 2009) which is devoted to "the study of service systems, aiming to create a basis for systematic service innovation" (Maglio and Spohrer, 2007). Many frameworks, good practice codes, models and standards have been developed as contributions to ITSM (Cater-Steel, 2009). Among these instruments, and beyond the more general quality management standard ISO 9001, and in addition to the ITIL (Information Technology Infrastructure Library)(OGC, 2011), which is the most widely disseminated framework in ITSM (Marrone and Kolbe, 2011a), ISO 20000 has been developed as the only international standard that specifically defines the requirements for a service management system.

International management standards - also referred as meta-standards - like ISO 20000, ISO 9001, ISO 14001 and ISO 27001, establish ways to systematise and formalise a whole series of processes into a set of procedures, and to document this implementation. They standardise procedures, duties and roles rather than goals or outcomes (Heras et al., 2010).

A common characteristic of these meta-standards is that they are, basically, collections of explicit requirements that should be fulfilled when implementing and operating the actual management system. Consequently an appropriately qualified person can audit the system, checking the system and the evidence against the requirements of the standard. In fact, the establishment of regular internal audits is a common requirement of these meta-standards.

Moreover, organizations can rely on external entities to certify their compliance with a meta-standard, like ISO 20000. Those external, independent entities, known as certifiers, usually issue formal certificates that organizations tend to publish them. These certificates are significant when studying the impact of the standard because, thanks to them, certified organisations have tangible evidence of having fully applied the standard and operated the management system.

Auditability and the possibility of certification is a marked difference between ITIL and ISO 20000. In fact, ITIL can be implemented partially or at different levels (Iden and Eikebrokk, 2014a) and nobody can strictly claim compliance with ITIL, as can be claimed, and demonstrated, for the case of ISO 20000, adding a level of certainty and establishing a solid foundation for research on the benefits of ITSM techniques.

However, until now, ISO 20000 has been somewhat eclipsed by ITIL or, at least, the two have frequently been confused. ITIL was the major inspiration for ISO 20000, so there is an overlap between the two - partly real and partly imaginary - that can be interpreted as either a benefit or a drawback. Although the two standards have a lot in common (Dugmore and Taylor, 2008), their natures are quite different. 
At this point, factors such as the relatively recent establishment of the standard and the aforementioned lack of visibility have led to a lack of specific research on ISO 20000. Although there has been a considerable amount of research in the field of ITSM, some focused specifically on its benefits (Marrone and Kolbe, 2011a), very little has focused on ISO 20000. Thus, the standard's current level of maturity and its foreseeable impact invite a more detailed study, of the kind that is presented here.

In what follows, the paper starts with a brief overview of the ISO 20000 standard, followed by the research objectives on the benefits of the certification. This leads to the proposal of a set of hypotheses. Then the methodological approach, based in a survey and Structural Equation Modelling (SEM) analysis is introduced as a way to test the hypotheses. Next, the findings section includes a general description of the sample to explain more foully the characteristics of the organizations certified, the identification of the benefits that those organizations experience, the identification of the hidden factors underlying those benefits and the validation of the hypotheses using an SEM model. Next, some research limitations are discussed. Finally the conclusions section provides further analysis and interpretation of the results.

\section{2- ISO 20000 overview}

ISO 20000 is a powerful tool for those looking for quality service management, whether they are IT-sector enterprises, IT departments or internal providers within some other kind of organisation or even other types of service-oriented organisations. It is relevant to note that, although the origin of the standard is rooted in an intention to manage IT services, the current version contains no impediment to using it for other types of services (Agrasala, 2013).

The ISO 20000 standard is composed of a series of documents. The first document, formally known as ISO/IEC 20000-1(ISO/IEC, 2011), is the only part that establishes requirements for a service management system, and therefore, these requirements are the only ones that must be complied with to obtain certification.

The other documents, even though they are very valuable and helpful for implementing the standard, can be considered complementary(ISO/IEC, 2010, 2012, $2013 \mathrm{a}, 2013 \mathrm{~b}, 2013 \mathrm{c})$. This is the reason why the first part is frequently considered to be the entire standard, as is done in this study. The current (2011) version of the standard is the first revision since the previous 2005 version, which was adapted from the pre-existing British Standard BS-15000.

The contents of the first part of the standard may seem familiar in their general form to those used to other quality management standards, for example, ISO 9001(Piskar and Dolinsek, 2006), from which it inherits much of the formal part, while containing more detailed, specific requirements according to the services to be managed. As noted above, the standard will be also familiar to those who know ITIL. While it is different in form, the concepts and terminology are mostly shared, especially with ITIL Version 2, which was the current version at the time when ISO 20000 was first published.

Like other international meta-standards, the text of the first part of the standard (ISO/IEC, 2011) is structured into chapters and clauses. Following the introduction, scope and references, the standard includes the general requirements for the management-system, such as requirements for documentation management, responsibility, governance of processes operated by other parties, resource management or how to establish and improve the management system, the requirements to deploy 
and retire new or changed services and, finally, four groups of processes, for a total of thirteen processes that focus respectively on: service level, reporting, continuity and availability, budgeting and accounting, capacity, information security, business relationships, suppliers, incidents and service requests, problems, changes, configuration and finally, release and deployment (Cots and Casadesús, 2013).

An implementer should construct his or her own service management system by formally documenting policies, plans, processes and procedures that meet these requirements.

The inspiration from ITIL v2 and its design to cover the specificities of service management (Iden and Eikebrokk, 2014b) makes ISO 20000 different from more general meta-standards like ISO 9001. The closer focus on services enables ISO 20000 to have higher and more specific requirements that would not fit in a general-purpose standard. In addition, if desired, ISO 20000 and ISO 9001 can both be implemented in a single management system (Simon et al., 2012), as is proposed by the standard ISO 90006 (ISO/IEC, 2013d), titled "Guidelines for the application of ISO 9001:2008 to IT service management and its integration with ISO/IEC 20000-1:2011".

\section{3- Objectives and hypothesis}

In the field of ITSM (Gacenga et al., 2010; Marrone and Kolbe, 2011b; Iden and Eikebrokk, 2013) and in the general study of management standards, there are only a few papers focused specifically on the study of ISO 20000 (Disterer, 2009, 2012; Cots, 2012, 2014; Cots and Casadesús, 2013, 2014; Tanovic et al., 2013; Walker et al., 2014).

Previous studies show that the diffusion slope of ISO 20000 is rapid and that this standard has reached a stage of maturity - close to its theoretical level of saturation in the certification market - quicker than previous management standards (Cots, 2012; Cots and Casadesús, 2014).

This makes it possible to explore the benefits of ISO 20000, which the previous literature has analysed only superficially. Only Disterer (2012) has addressed the benefits of 20000 certification, to a limited extent, using an approach which is similar to the study of other management systems - specifically, the most widespread systems, which are ISO 9001 and ISO 14001 - as a contribution to the research in the ITSM field.

Consequently, the main objective of this research is to identify and better understand the benefits of ISO 20000 implementation and their relationship with the general level of satisfaction with this standard, by collecting and analysing the opinions of those who have experience of ISO 20000 implementation and certification. This does not mean that an organisation cannot achieve the same benefits without certification or by applying a different approach to the use of this standard, except for those benefits specific to the prestige of the certification and its market recognition.

The first objective is to identify the benefits of certification and to evaluate the level of agreement on perceived benefits.

Second, and beyond the descriptive analysis, this research aims to find the hidden factors that contribute to the perceived benefits, by adopting and adapting the classification of internal and external benefits, which has already been well established by previous studies on management systems (Carlsson and Carlsson, 1996; Gotzamani and Tsiotras, 2002). External benefits are those related to the public recognition of certification, while internal benefits are those concerning organizational improvement 
or, in other words, the benefits that would be experienced even if nobody outside the organization knew of the existence of the management system or compliance with the standard. To analyse those constructs and differentiate between the two types of benefits, two hypotheses are proposed:

H1: ISO 20000 implementation has internal benefits.

H2: ISO 20000 implementation has external benefits.

The third objective is to determine the extent to which the different benefit-items contribute to the external or internal benefit construct.

Fourth, this paper analyses the possible causal relationship between these two kinds of benefits and the general satisfaction with ISO 20000 certification, by proposing the following hypotheses:

H3: ISO 20000's internal benefits have a positive impact on satisfaction.

H4: ISO 20000's external benefits have a positive impact on satisfaction.

And lastly, even though it is important to distinguish between internal and external benefits, it would also be interesting to determine if they are correlated, meaning to test whether those perceiving internal benefits perceive external benefits too, and vice versa, as described in the final hypothesis:

H5: ISO 20000's internal and external benefits are correlated.

\section{4- Methodology}

A specific survey, addressed to the top managers in charge of the ISO 20000 management system, was designed in order to gather information for solving the previous hypothesis. The tool selected for the survey was a specifically designed questionnaire, which, in addition to information describing each organisation, assessed a list of concepts related to motivation, key success factors, benefits and integration. The actual questions, specifically those related to benefits, were adapted from previous relevant works on other management standards, specifically those of Buttle (1997), Corbett et al. (2003) and the only previous study specific to ISO 20000 by Disterer (2012). Each question was formed using a common introductory sentence plus a specific question about how ISO-20000 certification contributed to obtaining various defined benefits. There was also a single question about general satisfaction with ISO 20000 and its certification.

To evaluate the questionnaire, a pilot test was conducted with 9 experts ( 3 academics and 6 practitioners) and the instrument was revised on the basis of their suggestions.

Another issue involved building a list of participants. There was uncertainty about the number of organisations in the population because of the lack of an official register of certificates. Unfortunately, no register of certificate was available either in Spain or globally. For this study, a list of ISO-20000-certification registers was constructed and (as far as possible) verified by starting with an unofficial list, then conducting an exhaustive Internet search (including search engines and social networks) and finally soliciting help from several consulting firms and support from the Spanish chapter of the itSMF (IT Service Management Forum).

This process provided the confidence that the number of certified organisations that sometime have had an ISO 20000 certificate in Spain was close to 186 - including those that subsequently went out of business. An attempt was made to contact to all the 
organisations through every means possible in order to obtain an email address for the top manager of the ISO 20000 management system. A valid and confirmed e-mail address was gathered for 149 organisations, and that was the number of surveys that ultimately were sent. The survey was conducted from May to July of 2013 and was addressed to all of the known and contactable ISO-20000-certified companies in Spain. Finally, 105 valid responses were collected - a 70.46\% response rate - each from a qualified individual in one of the selected organisations.

A descriptive analysis of the data gathered is presented in the results section, specifically focusing on the benefits achieved. However, a wider descriptive analysis of the survey is available in the final research report (Cots, 2014).

The methodology used to assess the aforementioned hypotheses is based on SEM, a multivariate statistical technique that is widely used in the literature, which aims to explain causality based on analysis of covariance. SEM has become a widely used research tool. Its attractiveness can be attributed to two factors: (i) it draws upon the notion of observed or latent variables, that will be useful in our case in order to establish the benefit constructs (see Figure 1), and (ii) SEM adopts the notion of modelling direct and indirect relationships (as represented by the last three hypotheses in our model in Figure 1).

The analysis is split into two steps. The first one is to validate a scale to assess the benefits of implementing the standard and consequently analysing hypotheses $\mathrm{H} 1$ and $\mathrm{H} 2$. Once that is established, the second step analyses the extent to which the benefits are antecedents of satisfaction with using the standard, proposing a model that solves the other three hypotheses.

\section{5- Findings}

The survey provided the ability to study the benefits of certification and its relationship with general satisfaction. In this section, first there is a description of the characteristics of the participating organisations, followed by an exploratory factor analysis and a confirmatory model of benefits to determine latent factors. Finally, a more complete model was created to test the relationship between those factors and general satisfaction with the implementation of ISO 20000.

\subsection{Description of the sample}

A summary of the main characteristics of the sample is shown in Table 1. The most relevant facts to be noted are that most of the participating organisations, as could reasonably have been anticipated, belong to the IT sector $(85 \%)$. Consistent with the prevalence of IT companies, in the majority of the organizations, in whatever sector they operated, the IT department represents over half of the total employees.

Another relevant characteristic that distinguishes the participating companies is whether they offer consulting or training on ISO 20000, as is the case for $32 \%$ of those companies. It should be taken into account that this characteristic could influence the intention to answer based on financial interests, which would probably bias the responses toward optimistic views. However, the fact that an ISO 20000 certified company provides services related to the same standard should not be surprising; indeed, in the early stages of the development of the market for certification, it is even natural. Moreover, this activity means that in many cases, respondents in this group have greater knowledge of and experience with the standard and, therefore, can make an especially valuable contribution and have well-founded opinions. 
With respect to company size, the companies were categorised solely by number of employees, partially following the criteria of the European Commission's Recommendation 2003/361/EC. Thus, companies with fewer than 10 employees were classified as micro-enterprises; those with fewer than 50 employees were classified as small businesses; those with 50 to 250 employees were classified as medium-sized; and those with more than 250 employees were classified as large.

To learn the details of companies' certification, we first analysed the year of initial certification and the version of the standard used (either 2005 version or the 2011 version). It was observed that the number of certified companies increases up to 2010, when the trend reversed, with a decline beginning in 2011 and 2012. These results are consistent with previous, worldwide studies (Cots and Casadesús, 2014). As mentioned above, a specific Spanish characteristic is the existence of public campaigns, which in the past have provided grants for obtaining ISO 20000 certification. The impact of these campaigns was so great at the time that companies that used them represented a majority of the sample $(60 \%)$. The drastic reduction of subsidies in recent years may also be a key factor explaining the reduction in the number of certificates issued in Spain beginning in 2011 and raises a question about the long-term sustainability of obtained certifications.

It should be noted that $89 \%$ of respondents were maintaining the certification and only 12 organizations have dropped it. Including these latest organizations is a useful counterpoint that helps the whole analysis.

Table 1- Sample characteristics

\begin{tabular}{|c|c|c|}
\hline \multicolumn{3}{|l|}{ Sector } \\
\hline & IT & $84.8 \%$ \\
\hline & Science and technology & $7.6 \%$ \\
\hline & Education/Universities & $2.9 \%$ \\
\hline & Transportation & $1 \%$ \\
\hline & Energy & $1 \%$ \\
\hline & Industry/Manufacturing & $1 \%$ \\
\hline & Financial services/Insurance & $1 \%$ \\
\hline & Distribution & $1 \%$ \\
\hline \multicolumn{3}{|c|}{ Number of employees } \\
\hline & $<10$ & $21 \%$ \\
\hline & $10-40$ & $44 \%$ \\
\hline & $50-250$ & $18 \%$ \\
\hline & $>250$ & $17 \%$ \\
\hline \multicolumn{3}{|c|}{ Employees in IT department } \\
\hline & $<10 \%$ & $21 \%$ \\
\hline & $10 \%-49 \%$ & $21 \%$ \\
\hline & $50 \%-95 \%$ & $40 \%$ \\
\hline & $>95 \%$ & $18 \%$ \\
\hline \multicolumn{3}{|c|}{ Offering consultancy or training on ISO 20000} \\
\hline & Yes & $32 \%$ \\
\hline & No & $68 \%$ \\
\hline \multicolumn{3}{|c|}{ Ownership } \\
\hline & Public & $7 \%$ \\
\hline & Private & $93 \%$ \\
\hline \multicolumn{3}{|c|}{ Users of services under certification scope } \\
\hline & External clients & $67 \%$ \\
\hline
\end{tabular}




\begin{tabular}{cc}
\hline $\begin{array}{c}\text { Other organisations } \\
\text { Internal users }\end{array}$ & $47 \%$ \\
Used public grant to certify & $57 \%$ \\
Yes & $60 \%$ \\
No & $40 \%$ \\
Implementation project cost & \\
$<€ 501$ & $9 \%$ \\
$€ 501-€ 3,000$ & $12 \%$ \\
$€ 3,001-€ 6,000$ & $7 \%$ \\
$€ 6,001-€ 18,000$ & $28 \%$ \\
$€ 18,001-€ 60,000$ & $29 \%$ \\
$>€ 60,000$ & $16 \%$ \\
\hline
\end{tabular}

The average duration of an implementation project is 8.29 months, with projects ranging from 2 to 24 months and the most common duration being 6 months. Relatively few projects last longer than one year.

With respect to the total cost of implementation, grouping the companies that declare a project cost, including tools, of less than $€ 3,000$ (21\%) seems to indicate that it is possible to implement ISO 20000 and obtain certification at a cost lower than previous standards (Karapetrovic et al., 2010). Conversely, 45\% of companies declare more than $€ 18,000$ as the cost of implementation. With respect to maintenance costs, the pattern is repeated: $45 \%$ of companies spend more than $€ 6,000$ per year on the management system (including tools), whereas another $45 \%$ invest virtually nothing (less than $€ 500$ ).

Finally, note that $60 \%$ of these companies state that they have an ISO 9001 certificate $-37 \%$ integrated with ISO 20000 - and that about $51 \%$ declare to use ITIL formally, while $40 \%$ just use it as a reference and only $9 \%$ feel that it is alien to them.

\subsection{ISO 20000 Benefits}

To gather the perceptions of the benefits of ISO-20000 certification, a list of 14 questions was included in the questionnaire presented to each respondent (see first column in Table 2).

Each respondent was asked to qualify his level of agreement with each sentence according to a Likert scale ranging from 1 ("Not at all") to 5 ("Absolutely"). It should be noted that 3 is half way between 1 and 5 , and should be interpreted as a medium perception of a particular benefit, not as a neutral opinion. It was expected that if a particular benefit was not perceived at all, a respondent would answer 1. Moreover, an eventual low score on a particular benefit should not be interpreted as evidence of the contrary disadvantage (i.e., the absence of economic benefits could not be interpreted as an economic loss).

Table 2 summarizes the analysis. The first column shows the 14 benefits; the second the label attached; the third and forth the means and standard deviations; next two columns show the Exploratory Factor Analysis (EFA) which is discussed in next subsection. The right hand section of the table includes the Confirmatory Factor Analysis (CFA) that is analysed in subsection 5.4. In all of these analyses, the robust maximum likelihood method from the asymptotic variance-covariance matrix was used. Finally, the Table 2 includes data for the general satisfaction that is used in the model tested later. The table is sorted from highest to lowest mean, to easily show the order of respondents' perception of the benefits. 
It can be observed that the means of most of the benefits (11 of 14) are above the level 3 (labelled as "Average") with typical deviations between 0.91 and 1.23. Because the highest mean is 3.71 and the lowest is 2.81 , all of the proposed benefits are positive, showing that every benefit is perceived to have been attained, but to different extents.

\subsection{Assessment of the benefit scale}

Until now, all of the benefits assessed have been valued as equivalents (except for their levels of "perception" or consensus), but it is clear that not all of them contribute in the same way or give the same weight to satisfaction in implementing ISO 20000.

The first step of the assessment is the exploratory factor analysis (EFA). The scale was analysed in accordance with the Kaiser-Guttman rule (Loehlin, 2004), selecting two factors with eigenvalues above the 1.0 cut-off. This leads us to propose the existence of two latent factors for ISO 20000 benefits.

Once this two-factor distribution has been established, Table 2 shows the variable's loading on each factor. The variables with a loading above 0.7 on one factor were selected as clearly contributing to the explanation of that factor. This analysis excluded 3 variables which did not load enough on either factor, leaving 11 variables: 8 explaining one factor and 3 explaining the other. See the model in Figure 1.

\subsection{Confirmatory factor analysis (CFA)}

The reliability of these two factors was then assessed. The composite reliability indicators greatly exceed the threshold value of 0.7 , confirming internal consistency. For each scale, the average variance extracted (AVE) estimate is higher than 0.50 .

Based on the variables that explain each factor, it is feasible to identify those variables as internal and external benefits, and this conclusion is consistent with the classification found in the literature for benefits provided by other standards (Casadesús et al., 2001). After the CFA was performed to evaluate consistency, and having mapped the first factor to internal benefits and the second to external benefits, H1 and $\mathbf{H 2}$ were accepted. It is clear that those who have implemented and certificated service management systems according to ISO 20000 perceive both internal and external benefits. 


\section{Benefits}

Marketing argument, confidence and/or reputation

Improved services through continuous-improvement method

Impulse standardisation, increased uniformity and consistency of

processes and services

Increased ability to plan and control

Satisfying a present or future demand of clients or regulators

Increase in user and client orientation and satisfaction

Competitive advantage

Making staff aware and/or establishing a quality culture

Improving the capacity to recover from an incident, error or catastrophic

event

Reducing incidents, errors and deviations

Enabling retention of knowledge and /or the introduction of new staff

Establishing audits

Reducing costs, increasing financial benefits or improving productivity

Increasing staff motivation

\section{Satisfaction}

General satisfaction with ISO 20000 implementation
CFA

EFA

Internal External Internal

Benefits Benefits Benefits

Load $^{\mathrm{a}} \quad$ Load $^{\mathrm{a}} \quad$ Stand $\mathrm{t}-$

Label Mean Std dev

$\begin{array}{lll}\text { B.MRKT } & 3.71 & 0.95\end{array}$

B.CONTI $3.68 \quad 0.96$

B.STD $\quad 3.67 \quad 0.92$

B.PLAN $\quad 3.51 \quad 0.97$

B.EXIG $\quad 3.51 \quad 1.12$

B.SATISF $3.49 \quad 1.02$

$\begin{array}{lll}\text { B.COMP } \quad 3.48 & 1.22\end{array}$

B.CULT $3.44 \quad 0.97$

B.REC $\quad 3.37 \quad 1.03$

$\begin{array}{lll}\text { B.INC } & 3.23 & 1.02\end{array}$

B.KNOL $\quad 3.10 \quad 0.96$

B.AUDIT $2.98 \quad 0.99$

$\begin{array}{lll}\text { B.PROF } & 2.97 \quad 1.07\end{array}$

\begin{tabular}{lll} 
B.MOTIV $2.81 \quad 0.98$ \\
\hline
\end{tabular}

0.73

0.73

0.71

0.74

0.60

0.72

0.78

0.82

0.79

0.61

0.71

0.69

0.80

0.80

$0.77 \quad 6.90$

Load $^{\mathrm{b}}$ value

External

Benefits

Stand t-

$\begin{array}{ll}\text { Load }^{\text {b }} & \text { value } \\ 0.74 & 7.62\end{array}$

\begin{tabular}{lll} 
Cronbach's alpha & 0.90 & 0.82 \\
Composite reliability & 0.91 & 0.83 \\
Average variance extracted (AVE) & 0.55 & 0.61 \\
\hline
\end{tabular}

EFA, exploratory factor analysis; CFA, confirmatory factory analysis.

${ }^{a}$ Blank cells have a loading below 0.3.

${ }^{\mathrm{b}}$ All significant at $\mathrm{p}$-value $=0.01$. 


\subsection{Causal Model}

Once the latent variables have been determined, the model proposed, as presented in Figure 1, includes the variable of directly measured global satisfaction, allowing the testing of $\mathrm{H} 3, \mathrm{H} 4$ and $\mathrm{H} 5$. The structural equation modelling (SEM) assesses simultaneously the paths and correlations suggested by the model. The results are presented in Table 3. The indices of goodness of fit support the conclusions. The Satorra-Bentler scaled chi-square is 60.60 on 52 degrees of freedom and its associated probability value is 0.194 . The comparative fit index (CFI) is 0.981 , and the root meansquare error of approximation (RMSEA) is 0.041 . Together, these results allow us to rely on the analysis and accept the three remaining hypothesis.

Confirming $\mathbf{H 3}$ and $\mathbf{H 4}$ makes it possible to assert that the identification of internal and external benefits causes general satisfaction with the standard implementation for those who implemented and certified a service management system according ISO 20000.

Furthermore, $\mathbf{H 5}$ implies that internal and external benefits are correlated, or that they do not come separately. Those who perceive one kind of benefit also get the other, while those who do not perceive one, generally do not get the other either.

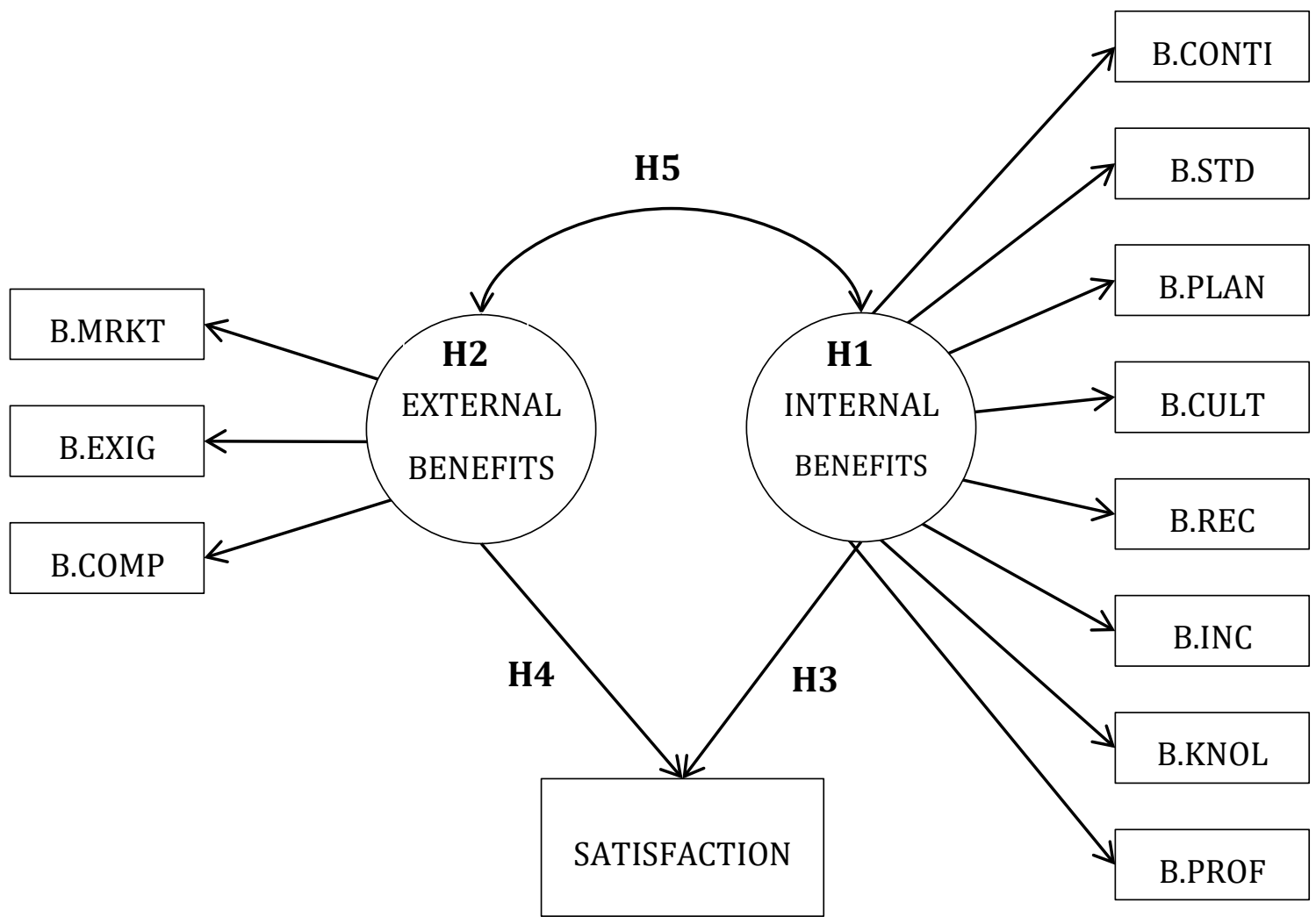

Figure 1 -Causal model

Table 3- Standardised solution of causal model

\begin{tabular}{lllcc}
\hline & & & Coefficient & t-value \\
\hline H3 & Path & Internal Benefits->Satisfaction & 0.37 & 3.56 \\
H4 & Path & External Benefits->Satisfaction & 0.39 & 3.87
\end{tabular}




\subsection{Limitations}

The main limitations of this study, which are very common in this type of research, are the specificities of the Spanish certification market, the size of the sample and the overlap in benefits arising from the standard compared with the benefits arising from the certification itself.

With respect to the first limitation, we note that Spain is one of the countries with higher certification intensity for ISO 20000 and for other standards at worldwide scale. The Spanish ISO20000-certification market was encouraged through two public funding programmes called "Avanza" and "Avanza2", which provided qualifying companies the opportunity to become certified at no cost. Although the funding source should have only a small impact on the benefits obtained, it is clear that it may have affected the composition of the certified population because it is likely that some organisations would not have sought certification if they had been required to assume the cost. Moreover, the existence of public funding provided consulting firms with a powerful argument when selling certification projects. While it is not clear how the economic support affected the composition of the population, it will be venturous to conclude that this support had impacted on the implementation benefits. It would be wise, therefore, to be cautious with generalization of the results to other countries, which, in their turn, may have their own peculiarities.

The size of the study sample is a consequence of its scope. Although Spain is a country with a high concentration of certified organisations on ISO 20000, as well as on other standards (Cots and Casadesús, 2014), and the response rate was high, the total number of certificates in Spain is obviously limited. An international study could include a bigger and a more diverse population, and, as is always the case, the bigger the sample the better.

In order to apply the SEM technique, and according to Iacobucci (2010) when cites Anderson and Gerbing (1984) "three or more indicators per factor, a sample size of 100 will usually be sufficient for convergence", going even further when noting: "It is of some comfort that SEM models can perform well, even with small samples (e.g., 50 to 100). The vague, folklore rule of thumb considering requisite sample size, e.g., ' $\mathrm{n}>200$ ' can be conservative, and is surely simplistic." Taking that into consideration, the sample of 105 should be enough to perform the analysis and to have some confidence in the results.

Another obvious limitation is that all of the participating organisations were certified, as no way could be found to identify organizations that had not gained the certification. However, including 12 organizations that dropped their certifications helps to have a broader sample.

One could also consider that not all benefits appear within the same time frame and not all of the participating organisations had operated their management systems for the same length of time. On the one hand the results are the product of this detected heterogeneity, while on the other hand the sample size is not big enough to segment it and establish different patterns depending on the years of ISO 20000 implementation or other factors. This could be a good point of departure for a future wider study.

Finally it should be noted that there is no easy way to distinguish between the benefits obtained from the standard implementation and those obtained from certification itself. Whether a particular benefit can be obtained without certification depends on the nature of that benefit. Obviously, it is not necessary to obtain a certificate to derive the benefits of the use of the standard, at least for those benefits that are internal. 


\section{6- Discussion and Conclusions}

Once the classification is analysed and their relationships established, it is feasible to analyse the benefits briefly and extract some conclusions.

Ordering the benefits shows their relative importance. It arises, among the rest, the external benefits: the marketing argument, confidence and/or reputation, the ability to satisfy a present or future demand of clients or regulators and the competitive advantage. This needs to be contextualised by the relative novelty of the standard. Organizations adopting a standard at an early stage - early adopters - gain a certain differential advantage by having a certification that few others have. Also, they can appear to be innovative organizations. As long as few certificates exist, the owning of one clearly separates an organization from its competitors. This effect may disappear over time as there are more certificates or the seal loses its novelty factor (Karapetrovic et al., 2010). Moreover, this benefit in the case of ISO 20000 probably relies on the prestige of ISO as institution that is very well known in relation to other standards, like ISO 9001 and even the prestige of certifiers that are well established and well known companies. On the other hand, at the present time there are few, if any, clients or regulators demanding ISO 20000 certificates. The way most of the benefit can be interpreted is as a feeling of confidence in the face of possible future demands, or as the use of the ISO 20000 seal as a demonstration of their commitment to quality.

The second most recognized benefit is the improvement of services through the continuous improvement. A high perception on this internal benefit arises from improvement in the efficacy of the management system, as this is one of the objectives of the standard. The continuous improvement approach is a very common recommendation of management practices, like ITIL, and although it is not an explicit requirement of ISO 20000 it is deeply integrated in the standard.

Similar comments could be made about standardisation, increased uniformity and consistency of processes and services, making the organization more predictive and governable, the increased ability to plan and control and enabling retention of knowledge and /or the introduction of new staff are generic benefits of applying formal management techniques and frameworks. This formalization of management relies heavily on managerial conviction and support (Boiral, 2011). Making staff aware of and/or establishing a quality culture and increasing staff motivation are clear reflections of the internalization of the standard (Tarí et al., 2013; Allur et al., 2014) and depend heavily on its implementation.

The increase in user and client orientation and satisfaction and reducing costs, increasing financial benefits or improving productivity are benefits that are consequences of other benefits, especially the improvement of services. It is important to note that user and client orientation is not selected for the model, while it is clearly perceived. This is consistent with its nature, where clients are "external" but the improvement depends upon specific internal factors.

Improving the capacity to recover from an incident, error or catastrophic event and reducing incidents, errors and deviations are short term objectives that not only depend on the management system, but on other technical factors. The identification of these benefits is recognition of the contribution of the management system to these.

The establishment of audits is a specific benefit of management according to standards and cannot be extended to other frameworks like ITIL. While it is the lowest of the motivations for certification declared on the survey (Cots, 2014), it is not the least benefit. External audits are key when considering the supply chain effect (Corbett, 2006). While the effect of audits depends very much on the management (Alic and Rusjan, 2010), this effect should not be underestimated.

Beyond the specific benefits and in addition to the characteristics of the sample of organisations that have certified their service-management systems according ISO 20000 in Spain, which can be 
similar to those in other countries, this research is the first to arrive at certain conclusions about the benefits of implementing and certifying ISO 20000.

First, the order of agreement in the list of benefits itself provides evidence that the benefits are clearly perceived, enabling those interested to point to positive results of implementation and certification of ISO 20000. It is relevant to underline the fact that all the benefits proposed are widely perceived, albeit with different intensities. Even from these clearly positive results it should not been inferred that most of the benefits - especially internal benefits - could not be achieved by other means, which might include the implementation of other standards like ISO 9001, ITSM best practices frameworks like ITIL or even ad-hoc management practices.

Second, it is reasonable to classify the benefits of ISO 20000 into internal and external categories and to identify variables that best describe those benefits. External benefits can be defined, considering their order of importance as marketing benefits, responding to customers and their demands, and obtaining a competitive advantage. In parallel, internal benefits can be defined from the most important to the least as improving services, supporting service standardisation, increasing the ability to plan and control, establishing a quality culture, improving the capacity to recover from an accident, reducing incidents and enabling the retention of the organisation's knowledge.

Finally, this research shows that internal and external benefits make an important contribution to satisfaction, supporting the interpretation of the most relevant benefits and showing which of those benefits has a greater impact on satisfaction. The expected correlation between internal and external benefits confirms that frequently benefits are not isolated and organisations that perceive one type of benefit frequently also perceive others. Consequently, such organisations obtain satisfaction from ISO 20000 implementation and certification.

Conversely, even in the light of the limitations of this study, and exercising necessary caution, our results on the benefits of ISO 20000 can be seen as generic benefits of ITSM techniques, and therefore the present study can be seen as a stimulation to further investigation in this field.

In future, valuable steps in the research agenda on this issue will be analysis of the benefits of ISO 20000 for different kinds of organizations, according their size, geographical distribution or even motivation to certify. At the same time, it would be interesting to study on the integration with other management standards, a growing trend encouraged and facilitated by ISO itself by homogenising the format of its standards as they are updated. Finally, the actual success of ISO 20000 and its contribution to ITSM should be studied in greater depth, which will be of interest to practitioners and academics alike.

\section{References}

Agrasala, V. (2013), ISO/IEC 20000 for Generic (IT \& Non-IT) Service Management? | Vinod Agrasala's ITSM / ITIL Blog. Available from: http://vagrasala.wordpress.com/2013/02/28/isoiec20000-for-generic-it-non-it-service-management/.

Alic, M., and Rusjan, B. (2010), "Contribution of the ISO 9001 internal audit to business performance" International Journal of Quality \& Reliability Management Vol. 27, No. 8, pp. 916-937.

Allur, E., Heras, I., and Casadesús, M. (2014), “Internalization of ISO 9001: a longitudinal survey” Industrial Management \& Data Systems Vol. 114, No. 6, pp. 872-885. 
Anderson, J.C., and Gerbing, D.W. (1984), "The effect of sampling error on convergence, improper solutions, and goodness-of-fit indices for maximum likelihood confirmatory factor analysis" Psychometrika Vol. 49, No. 2, pp. 155-173.

Bitner, M.J. (2001), "Service and technology: opportunities and paradoxes" Managing Service Quality Vol. 11, No. 6, pp. 375 - 379.

Boiral, O. (2011), "Managing with ISO Systems: Lessons from Practice” Long Range Planning Vol. 44, No. 3, pp. 197-220.

Brocke, H., Uebernickel, F., and Brenner, W. (2010), "A methodical procedure for designing consumer oriented on-demand IT service propositions" Information Systems and E-Business Management Vol. 9, No. 2, pp. 283-302.

Buttle, F. (1997), "ISO 9000: marketing motivations and benefits" International Journal of Quality \& Reliability Management Vol. 14, No. 9, pp. 936-947.

Carlsson, M., and Carlsson, D. (1996), "Experiences of implementing ISO 9000 in Swedish industry" International Journal of Quality \& Reliability Management Vol. 13, No. 7, pp. 36-47.

Casadesús, M., Giménez, G., and Heras, I. (2001), "Benefits of ISO 9000 implementation in Spanish industry” European Business Review Vol. 13, No. 6, pp. 327-336.

Cater-Steel, A. (2009), Information technology governance and service management: frameworks and adaptations, Information Science Reference,.

Cherbakov, L., Galambos, G., Harishankar, R., Kalyana, S., and Rackham, G. (2005), "Impact of service orientation at the business level” IBM Systems Journal Vol. 44, No. 4, pp. 653-668.

Corbett, C.J. (2006), "Global diffusion of ISO 9000 certification through supply chains" Manufacturing \& Service Operations Management pp. 1-44.

Corbett, C.J., Luca, A.M., and Pan, J.-N. (2003), "Global perspectives on global standards" ISO Management Systems No. January-February.

Cots, S. (2012), "La estandarización de la gestión de TI a través de ISO / IEC 20000” VII Congreso Académico Internacional en Gobierno y Gestión del Servicio de TI, itSMF España Madrid,.

Cots, S. (2014), Impacto de ISO 20000. Un estudio empírico, Documenta Universitaria, Girona.

Cots, S., and Casadesús, M. (2013), "Implementing ISO 20000: proposals from learned lessons" $T M Q$ - Techniques, Methodologies and Quality No. 4, pp. 12-31.

Cots, S., and Casadesús, M. (2014), "Exploring the service management standard ISO 20000" Total Quality Management \& Business Excellence pp. 1-19.

Demirkan, H., Kauffman, R.J., Vayghan, J. a., Fill, H.-G., Karagiannis, D., and Maglio, P.P. (2008), "Service-oriented technology and management: Perspectives on research and practice for the coming decade" Electronic Commerce Research and Applications Vol. 7, No. 4, pp. 356-376.

Disterer, G. (2009), “ISO 20000 for IT” Business \& Information Systems Engineering Vol. 1, No. 6, pp. 463-467. 
Disterer, G. (2012), "Why firms seek ISO 20000 certification - A study of ISO 20000 adoption" ECIS 2012 Proceedings, Barcelona, Spain, Paper 31.

Dugmore, J., and Taylor, S. (2008), ITIL V3 and ISO/IEC 20000 Alignement White Paper.

Edvardsson, B. (1998), "Service quality improvement” Managing Service Quality Vol. 8, No. 2, pp. 142-149.

Gacenga, F., Cater-Steel, A., and Toleman, M. (2010), “An international analisys of IT service management benefits and performance measurement" Journal of Global IT Management Vol. 13, No. 4, pp. 28-63.

Galup, S., Dattero, R., Quan, J.J., and Conger, S. (2009), “An overview of IT service management" Communications of the ACM Vol. 52, No. 5, pp. 124.

Gotzamani, K.D., and Tsiotras, G.D. (2002), "The true motives behind ISO 9000 certification: Their effect on the overall certification benefits and long term contribution towards TQM" International Journal of Quality \& Reliability Management Vol. 19, No. 2, pp. 151-169.

Gupta, A., McDaniel, J.C., and Herath, S.K. (2005), "Quality management in service firms: sustaining structures of total quality service” Managing Service Quality Vol. 15, No. 4, pp. 389402.

Heras, I., Arana, G., and San Miguel, E. (2010), “An Analysis of the Main Drivers for ISO 9001 and other Isomorphic Metastandards" Review of International Comparative Management Vol. 11, No. 4, pp. 562-574.

Iacobucci, D. (2010), "Structural equations modeling: Fit Indices, sample size, and advanced topics" Journal of Consumer Psychology Vol. 20, No. 1, pp. 90-98.

Iden, J., and Eikebrokk, T.R. (2013), "Implementing IT Service Management: A systematic literature review" International Journal of Information Management Vol. 33, No. 3, pp. 512-523.

Iden, J., and Eikebrokk, T.R. (2014a), "Using the ITIL Process Reference Model for Realizing IT Governance: An Empirical Investigation” Information Systems Management Vol. 31, No. 1, pp. $37-58$.

Iden, J., and Eikebrokk, T.R. (2014b), "Exploring the Relationship between Information Technology Infrastructure Library and Process Management: Theory Development and Empirical Testing" Knowledge and Process Management.

ISO/IEC (2010), “ISO/IEC TR 20000-4 Information technology - Service management - Part 4: Process reference model."

ISO/IEC (2011), “ISO/IEC 20000-1 Information technology - Service management - Part1: Service management system requirements" Vol. 2011.

ISO/IEC (2012), "ISO/IEC 20000-2 Information technology - Service management - Part 2: Guidance on the application of service management." 
ISO/IEC (2013a), "ISO/IEC 20000-3 Information technology - Service management - Part 3: Guidance on scope definition and applicability of ISO/IEC 20000-1.”

ISO/IEC (2013b), "ISO/IEC TR 20000-5 Information technology - Service management - Part 5: Exemplar implementation plan for ISO/IEC 20000-1.”

ISO/IEC (2013c), "ISO/IEC 20000-10 Information technology - Service management - Part 10: Concepts and terminology."

ISO/IEC (2013d), "ISO/IEC TR 90006:2013 Information technology - Guidelines for the application of ISO 9001:2008 to IT service management and its integration with ISO/IEC 20000-1:2011.”

Karapetrovic, S., Casadesús, M., and Heras, I. (2010), "What happened to the ISO 9000 lustre? An eight-year study” Total Quality Management \& Business Excellence Vol. 21, No. 3, pp. 245-267.

Keel, a. J., Orr, M. a., Hernandez, R.R., Patrocinio, E. a, and Bouchard, J. (2007), "From a technology-oriented to a service-oriented approach to IT management" IBM Systems Journal Vol. 46, No. 3, pp. 549-564.

Loehlin, J.C. (2004), Latent variable models: an introduction to factor, path, and structural equation analysis, Lawrence Erlbaum Associates, Inc,.

Maglio, P.P., and Spohrer, J. (2007), "Fundamentals of service science" Journal of Academy of Marketing Science pp. 18-20.

Maglio, P.P., Vargo, S.L., Caswell, N., and Spohrer, J. (2009), "The service system is the basic abstraction of service science" Information Systems and E-Business Management Vol. 7, No. 4, pp. 395-406.

Marimon, F., Casadesús, M., and Heras, I. (2006), "ISO 9000 and ISO 14000 standards: an international diffusion model" International Journal of Operations \& Production Management Vol. 26, No. 2, pp. 141-165.

Marimon, F., Casadesús, M., and Heras, I. (2010), "Certification intensity level of the leading nations in ISO 9000 and ISO 14000 standards" International Journal of Quality \& Reliability Management Vol. 27, No. 9, pp. 1002-1020.

Marimon, F., Llach, J., and Bernardo, M. (2011), "Comparative analysis of diffusion of the ISO 14001 standard by sector of activity” Journal of Cleaner Production Vol. 19, No. 15, pp. 17341744.

Marrone, M., and Kolbe, L.M. (2011a), “Uncovering ITIL claims: IT executives' perception on benefits and Business-IT alignment" Information Systems and E-Business Management Vol. 9, No. 3, pp. 381-382.

Marrone, M., and Kolbe, L.M. (2011b), "Impact of IT Service Management Frameworks on the IT Organization” Business \& Information Systems Engineering Vol. 3, No. 1, pp. 5-18.

OGC (2011), ITIL Lifecycle Publication Suite - Books, TSO (The Stationery Office), 
Piskar, F., and Dolinsek, S. (2006), "Implementation of the ISO 9001: from QMS to business model" Industrial Management \& Data Systems Vol. 106, No. 9, pp. 1333-1343.

Sandström, S., Edvardsson, B., Kristensson, P., and Magnusson, P. (2008), "Value in use through service experience” Managing Service Quality Vol. 18, No. 2, pp. 112-126.

Simon, A., Karapetrovic, S., and Casadesús, M. (2012), "Difficulties and benefits of integrated management systems" Industrial Management \& Data Systems Vol. 112, No. 5, pp. 828-846.

Tanovic, A., Ribic, S., and Sehovac, Z. (2013), "New performed model of ISO/IEC 20000 standard" International Journal of Digital Content Technology and Its Applications Vol. 7, No. 10, pp. 8094.

Tarí, J.J., Heras, I., and Pereira, J. (2013), "Internalization of quality management in service organizations" Managing Service Quality Vol. 23, No. 6, pp. 1.

Walker, A., Coletta, A., and Sivaraman, R. (2014), "An evaluation of the process capability implications of the requirements of ISO / IEC 20000-1" Journal of Software: Evolution and Process.

Winniford, M., Conger, S., and Erickson-Harris, L. (2009), "Confusion in the Ranks: IT Service Management Practice and Terminology" Information Systems Management Vol. 26, No. 2, pp. $153-163$. 